\title{
How climate change is likely to influence the spatial distribution of Aedes aegypti and dengue fever in the Arab World \\ Dr. Hassan M. Khormi
}

Department of Social Sciences, College of Arts and Humanities, Jazan University

Jazan, Saudi Arabia.

hkhormi@jazanu.edu.sa 


\section{HOW GLIMATE GHANGE IS LIKEIY TO INFLUENGE THE SPATIAL DISTRIBUTION OF AEDES AEGYPTI AND DENGUE FEVER IN THE ARAB WORLD \\ Dr. Hassan M. Khormi \\ Department of Social Sciences, College of \\ Arts and Humanities, Jazan University Jazan, Saudi Arabia. \\ hkhormi@jazanu.edu.sa}

the national health services in the Arab World; especially where they are improving the early detection of mosquito favorable areas and dengue transmission, and striving for the prevention of dengue fever. The strategy presented here should be supported by a surveillance system sufficient to prevent the spread of this virus and the resulting public health threat.

Keywords: Aedes aegypti, Dengue transmission, CLIMEX, Arab World, Climate Change

Areas infested by Aedes aegypti usually record a high outbreak of dengue. The Aedes aegypti mosquito and dengue transmission are climate sensitive. In this study, we used simulation analysis to project different parameters, e.g. temperature, moisture, dryness and heat, and related alterations in order to establish the potential effects of climate change on the distribution of Aedes aegypti and dengue transmission in the Arab World. The study was based on different Climate Models (CMs) and scenarios, using CLIMEX. The two CMs used were CSIRO-Mk3.0 (CS) and MIROC-H (MR). These were run with the A2 SRES (Special Report on Emissions Scenarios) for 2050 and 2100. The model was calibrated using data from several knowledge domains, including geographical distribution records. The current climate model shows the favorability for Aedes aegypti and dengue transmission within most of the known areas in Saudi Arabia, Somalia, Sudan, Djibouti and Yemen. In the future models, we observed a general reduction or contraction in the very favorable climate areas. The models indicate a reduction in very favorable climate areas in 2050, and this trend was observed to be exacerbated by 2100 . New areas of favorable climate conditions are observed to appear in the north east of Oman and UAE, the west of Yemen and the north of Libya. A study of the models' results can help to reduce the challenges facing 


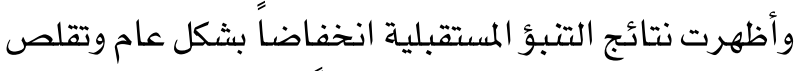

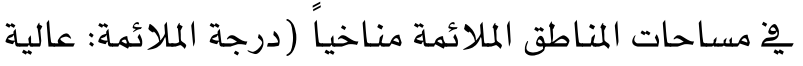
جداً ) لتوالد وانتشار البعوض الناقل لمرض حمى المنى الضنك.

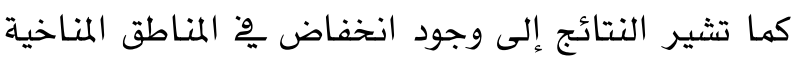

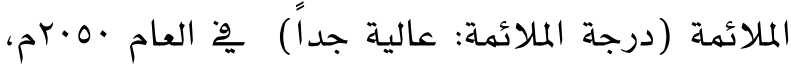

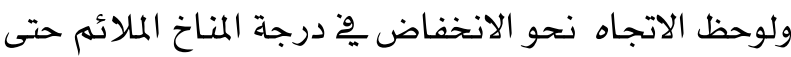

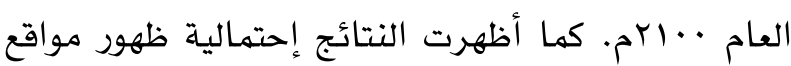
جديدة ذات بظروف مناخية ملائمة

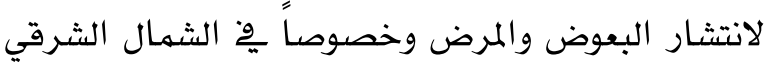

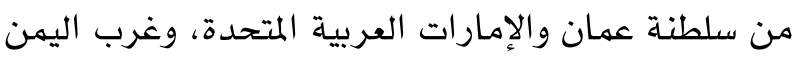

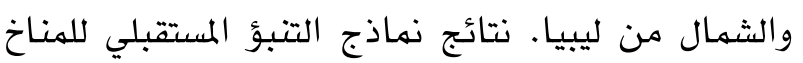

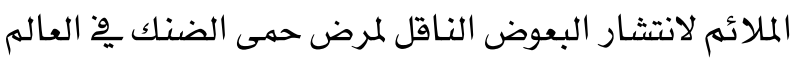

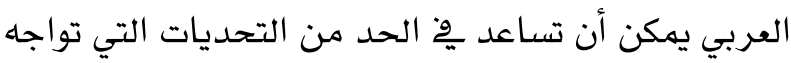

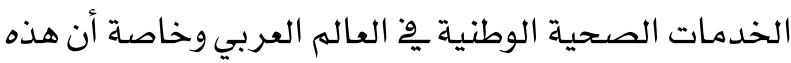
المنهجية تساعد وِّ الكثف المبكر عن المناطق الملائمة مناخياً لانتشار البعوض الناقل لحهى الضنك سعياً للوقاية منه.

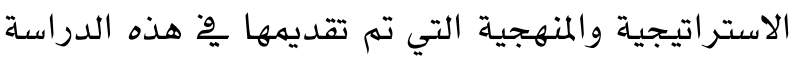

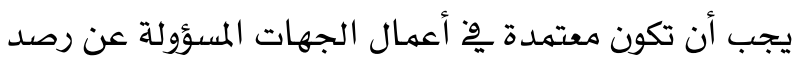

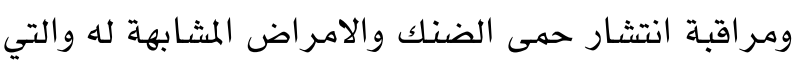
تهدد الصحة العامة يِّ العالم العربي.

كلمات البحث: الزاعجة المصرية ، حمى الضنك ، CLIMEX

\section{كيف لسيؤثر التغير المناخي على التوزيع المكاني الملستقبلي لبعوفة التزاعجة الممرية المبرية ومرض حمى المُنك في العالم العربي لمئي \\ د. حسن بن محسن خرمي \\ قسم العلوم الإجتماعية - كلية الآداب والعلوم

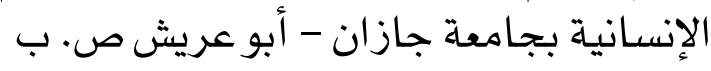

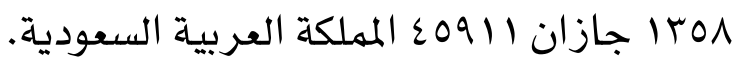

hkhormi@jazanu.edu.sa

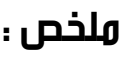

المناطق الموبوءة ببعوضة الزاعجة المصرية (الإيديس

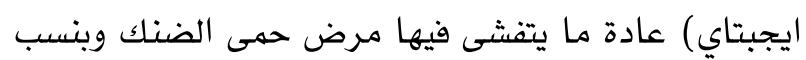

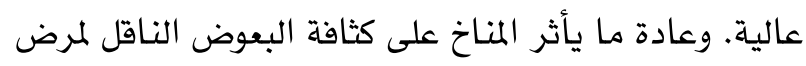

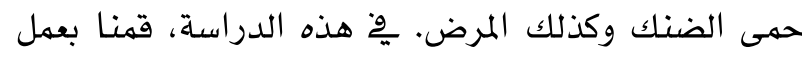
تحليل ومحاكاة بالإعتهاد على مجموعة من العناصر المناخية

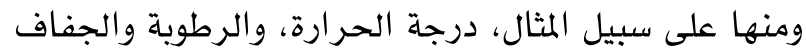

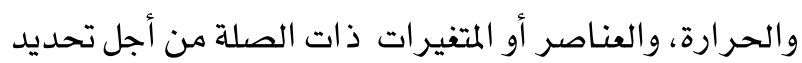

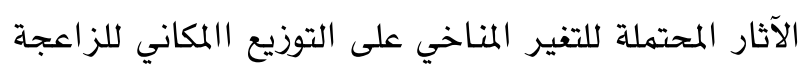

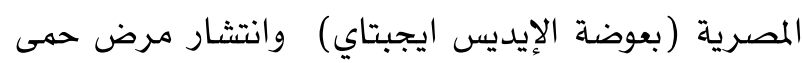

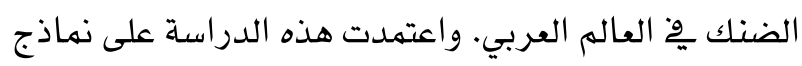
تنبؤ مناخية مختلفة (Climate Models) ومجمهوعة من السيناريوهات المتوقعة مستقبلاً، وذلك باستخدام برنامج كلايهكس (CLIMEX). تم استخدام اثنين من بن الثنات أشهر نماذج التنبؤ المناخية وهي (CSIRO-Mk3.0 (CS A2 الخاص بسنياريوهات انبعاث الغازات التي تؤدي للأنحباس الحراري (Special Report on Emissions) Scenarios

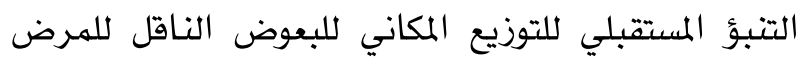

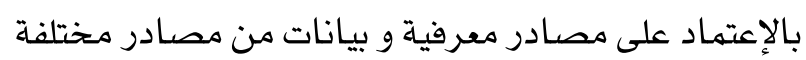

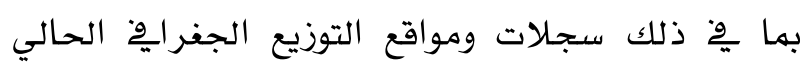

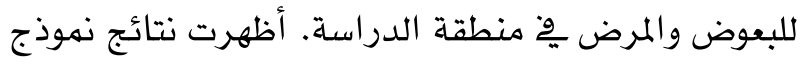
التنبؤ للمناخ الحالي بالأعتماد على بيانات للفترة من - 190

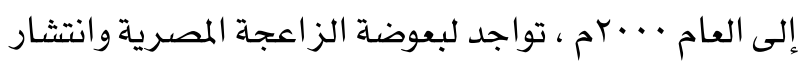
لحمى الضنك ِوْ معظم المناطق المعروفة حالياً بتأثرها بالمرض أو البعوض الناقل للمرض وبِّْ دول مثل المملكة العربية السعودية، والصومال ، والسودان ، وجيبوتي واليهن. 


\section{Background}

Climate has been known to be one of the fundamental forces behind the diseases affecting health. The recognition of climate change is growing, and has lead to an increased interest by researchers in measuring the potential mechanisms by which climate change can influence health [1]. Health can be impacted by climate change through a range of pathways, such as cold related deaths, and increased flood and drought related changes in the distribution of mosquito-borne diseases, e.g. dengue fever [2].

Dengue fever is one of the most important mosquito-borne diseases around the world. The current estimated data suggests that millions of dengue cases are recorded annually, especially in tropical and subtropical regions [3]. The main vector that transmits the disease is the Aedes aegypti mosquito. Unfortunately, no adequate vaccine or drugs yet exist to reduce the impact of the disease [4]. Therefore, to control and reduce the impact of the disease, authorities need to monitor and control the disease vector [5].

Areas infested by Aedes aegypti usually record a high outbreak of dengue fever. Aedes aegypti and dengue transmission are climatically sensitive. Many studies have investigated the role of climate in the dynamics of the Aedes aegypti [1, 5]. Climatic variables, such as temperature and moisture, significantly influence the mosquito's development and survival [6-9].

Transmission increases in warmer temperatures, raising the odds of dengue transmission, while reproduction rate and replication of the disease are slower in cooler temperatures [10]. In general, higher amounts of precipitation lead to an increase in the number of breeding sites of Aedes aegypti, and humidity is often overlooked as a factor in the life-cycle of the mosquito and in disease replication and transmission $[11,12]$. However, we have to consider the fundamental mechanisms that can help identify the important associations between climate and dengue vector ecology [13]. If we examine the fundamental climatic and ecological components of the disease phenomenon we can identify differences in the biophysical and socioeconomic drivers of spatial dengue and its vector patterns. Therefore, an increase in global temperature, and other associated climate changes, may affect and modify the geographical distribution and range of Aedes aegypti [1].

Worldwide, limited studies have been conducted to model the impact of climate change on the distribution of dengue and its vector (Aedes aegypti). For example, Patz et al. [14] used three general circulation models of climate change to project the temperatures related to alterations in potential dengue transmission resulting from the global climate scenarios of the The United Nations Intergovernmental Panel on Climate Change (IPCC) [15]. However, they focused only on one climate parameter, namely temperature. Other earlier studies did not assess the impact of climate change on the dengue and its vector quantitatively, but focused on demonstrating the climatic sensitivity of the determinants of dengue fever transmission [14, 16-20].

In the Arab World, a few studies have investigated the impact of climate on the proliferation of Aedes aegypti, or on dengue fever cases. For example, Khormi et al. [5] described the association between Aedes aegypti and relative humidity, temperature, and rainfall by quantifying the number of adult Aedes mosquitoes detected weekly over a five year period, from 2006 to 2010, in Jeddah, Saudi Arabia. Another study, conducted by Al-Ghamdi et al. [21], illustrated the role of climatic factors on the seasonal variations in the number of Aedes mosquitoes. Most of the other studies conducted to study areas in the Arab World (e.g. Saudi Arabia, Sudan, Oman and Yemen) illustrated the entomological characteristics of Aedes aegypti $[22,23]$, by determining the demographic, clinical 
and laboratory profiles [24-26] and by predicting vector populations[21, 27-29]. According to a literature survey conducted by the author [11], no published studies have considered the impact of climate change in the Arab world and the resulting effects on the distribution of dengue fever and its vector.

The suggestion has been made that the average global temperature may increase by between $2.0^{\circ} \mathrm{C}$ and $6^{\circ} \mathrm{C}$ between 1990 and 2100 [15, 30]. Of relevance to the disease distribution, minimum temperatures are now increasing at a disproportionate rate as compared to the average and maximum temperatures. This increase is predicted to continue under the anticipated climate change scenarios, and such conditions may allow dengue, its vector and other climatically sensitive mosquito-borne diseases to expand into regions previously free of the disease. Another suggestion is that such conditions may exacerbate transmission in the parts of the world to which it is endemic [15].

In this study, we used simulation analysis to project different parameters, e.g. temperature, moisture, dryness and heat, and the related potential alterations in climate change on the distribution of Aedes aegypti and dengue transmission, using different Climate Models (CMs) and scenarios.

To model the potential (future) distribution of Aedes aegypti, we used CLIMEX, which is a useful tool for identifying the association between the fundamental and realized niche of the species $[31,32]$. This is an eco-climatic modelling package. It has been used to estimate invasive species' potential distribution under current and future climatic conditions [32-35]. The realized niche of a species is the range of conditions and resources under which it can persist in the presence of competitors and predators, and this is represented as the native range of a species (e.g. Aedes aegypti) [36].

CLIMEX can be used to model the potential distribution of organisms, and draws upon a variety of information types, that include direct experimental observations of a species' growth response to temperature and soil moisture, its phenology and the knowledge of its current distribution [32].

In the present study, CLIMEX was used to develop a model of the climate responses of Aedes aegypti and dengue transmission, based on their current and invasive distribution in the Arab world. This model was then used to project their potential distribution under the current climate, using extensive distribution data for model validation, and to assess the impacts of climate change on potential distribution, using two climate models (CMs), CSIRO-Mk3.0 (CS) and MIROC-H (MR). These were run with A2 SRES (Special Report on Emissions Scenarios) for 2050 and 2100.

\section{Materials and Methods \\ Study Area}

This study was conducted in the Arab World. The Arab world consists of the Arabic-speaking states, territories and populations in countries situated in North Africa and Western Asia. It includes around 23 countries, extending from the Arabian Gulf in the east to the Atlantic Ocean in the west, and from the Horn of Africa and the Indian Ocean in the southeast to the Mediterranean Sea in the north. It is home to around 340 million people (Figure 1).

\section{Current distribution of Aedes aegypti in the} Arab World

The distribution figures for Aedes aegypti in the Arab World were collected from different sources, such as the Centre for Disease Control and Prevention (CDC) [37]; the Centre for International Earth Science Information 
Network (CIESIN) [38]; Gratz [39]; Gubler and Tent [40]; Gubler and Clark [4]; Gubler [41-45]; Gubler and Kuno [46]; Lounibos [47]; Medlock et al. [48]; Moore [49]; Moore and Mitchell [50]; Rogers et al. [51]; Khormi et al. [5]; Al Thbiani et al. [52]; Al-Ghamdi et al. [21]; Abdalmagid and Alhusein [22]; Mohamed et al. [23] ; Ayyub et al. [24]; Bin Ghouth et al. [25]; Al-Araim et al. [26]; Aburas [27]; El-Badry and Al-Ali [28]; Rodier et al. [53] and Sharp et al. [29]. The identified regions represent areas of ongoing transmission risk, and local and regional dengue or imported cases of dengue and Aedes aegypti, and are based on data from Ministries of Health, international health organizations, journals, and knowledgeable experts (See references above).

According to Gubler and Kuno [46], it is generally accepted that areas that are plagued by dengue fever are also infested by Aedes aegypti, as the main vector transmitting the disease. Figure 1 shows that most of the Aedes aegypti and dengue cases are found along the western coast of Saudi Arabia, Oman, Yemen, Somalia, United Arab Emirates (UAE), Sudan, south east of Egypt and Djibouti [54]. In Saudi Arabia, Italics is thought to be widespread, especially in Jeddah, Jizan, AL-Madinah AlMunawwarah and Makkah. In Yemen, dengue and its vector are mostly recorded in Hajjah, Al Hudaydah, Al Mukalla, Taizz and Mareb. Most of the dengue fever cases recoded in Oman and UAE were by importation, especially from South and South East Asia [23], but there are also a small number of cases recorded as residential. Dengue fever and Aedes are also found in Sudan, especially in East Sudan, and particularly in Port Sudan, Kassala, Elgadarief State and the Northern Province of Sudan. In Djibouti, dengue is recorded, e.g. in the city of Djibouti. In Somalia, it has been found, for example, in Hargeys. There are few controls directed specifically at dengue in Somalia, due to a number of reasons, including security. All the data obtained concerning Italics and dengue fever were used in establishing the parameters such as heat stress, cold stress, wet stress and temperature index.

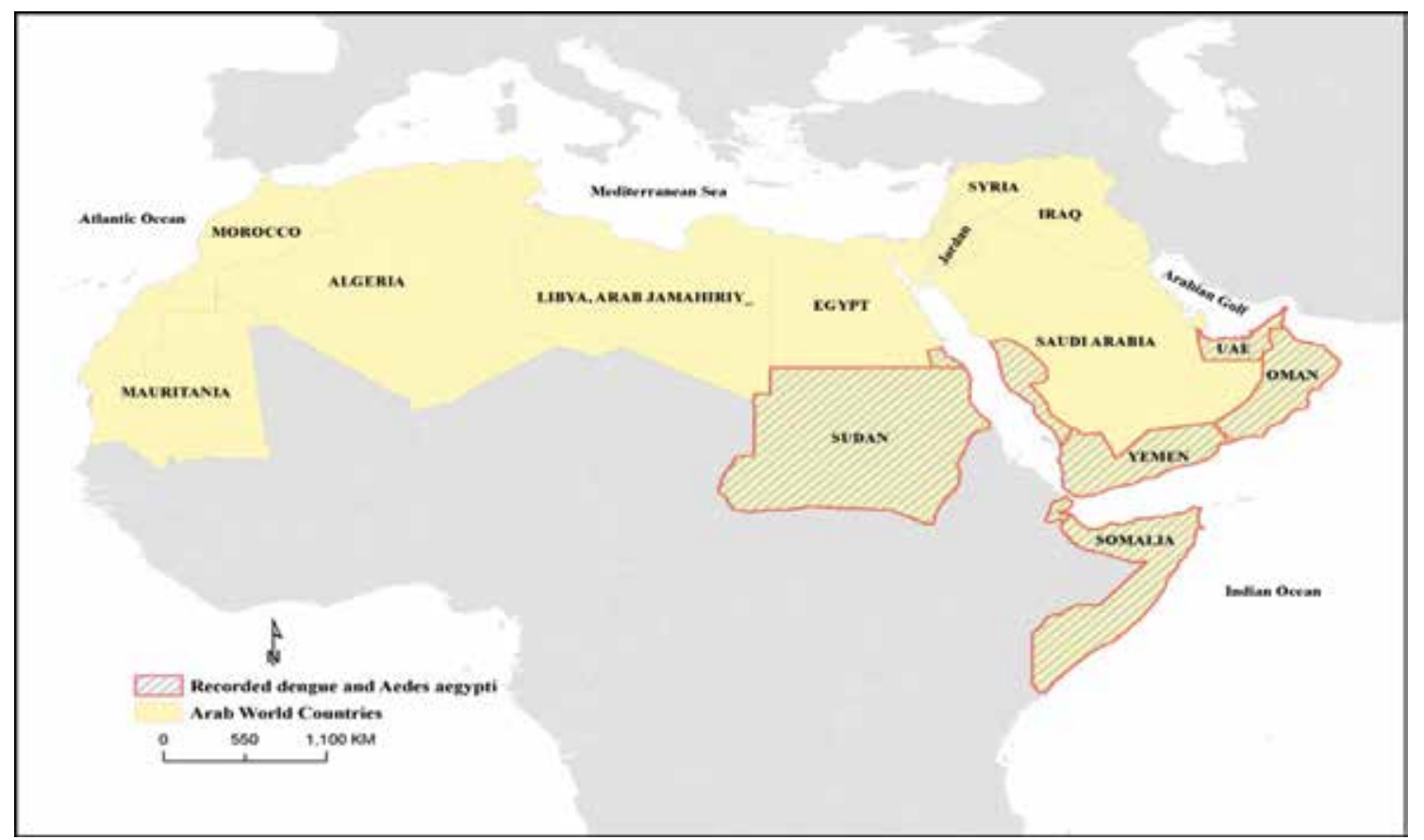

Figure 1: Study area and distribution of Aedes aegypti mosquito and dengue cases in the Arab World. 


\section{CLIMEX software}

Climateisthemain determinantof the distribution of plants and poikilothermal animals [55] and this is the key assumption behind CLIMEX. The software is dependent on the formation of an eco-physiological model. According to Sutherst et al. [56], this model assumes that a favorable season enables a species to flourish, and an unfavorable season causes population decline. CLIMEX users can infer parameters that explain a species' response to climate, based on phenological observations or on its spatial variety [56]. The Eco-climatic Index (EI) is an overall annual index of climatic suitability, based on weekly calculations of growth index (GIA) and stress index e.g. cold, wet, hot and dry. The EI is theoretically scaled from 0 to 100 . A species (e.g. Aedes aegypti) can become established if EI $>0$. If the value of EI is close to 0 , the probability of conditions conductive to persistence in time and space is low, and if the EI value is more than 20 , the probability of conditions conductive to persistence in time and space is very favorable $[32,56]$. Based on the data available for this software, we developed models of the potential distribution of Aedes aegypti under current and different future climatic scenarios.

\section{Climate Data and Climate Change Scenarios}

We used the CliMond 10' gridded climate data to model the potential distribution. To present the historical climate (averaging period 19502000) and the potential climate in 2050 and 2100, we used average minimum and maximum monthly temperatures ( $T_{\min }$ and $T_{\max }$, respectively), average monthly precipitation $\left(\mathrm{P}_{\text {total }}\right)$ and relative humidity at 9:00 h ( $\mathrm{RH}_{9: 00)}$ and 15:00 $\mathrm{h} \quad\left(\mathrm{RH}_{15: 00}\right)$ respectively. The potential distribution was based on two climate models (CMs), which are CSIRO-MK3.0 (CS) and MIROC-H (MR) (Centre for Climate Research, Japan) with A2 SRES scenarios [30,
57]. These models are available as part of the CliMond datasets. The MR model predicts that the temperature will increase by roughly $4.31^{\circ} \mathrm{C}$ by 2100 , while the CS model predicts a rise of $2.11^{\circ} \mathrm{C}$ by 2100 . There are also differences in rainfall patterns as predicted by the $\mathrm{CS}$ and $\mathrm{MR}$ models. For example, the CS model predicts a $14 \%$ decrease in future mean annual rainfall, whereas the MR model predicts only a $1 \%$ decrease.

We selected these two CMs (CS and MR) out of 23 possible $\mathrm{CMs}$ in the CliMond datasets because:1) the temperature, precipitation, mean sea level pressure and specific humidity variables required for CLIMEX were available for these two CMs; 2) the models have relatively small horizontal grid spacing; and 3) they performed well compared to other CMs in representing basic aspects of observed climate on a regional scale $[32,58]$. We selected A2 scenarios to typify the possible geographical range in relation to climate possibility of Aedes aegypti in 2050 and 2100. According to Kriticos et al. [58], A2 scenarios describe a varied world with high population growth, slow economic development and technological change. We selected the two project dates (2050 and 2100) as providing a reasonable snapshot of the foreseeable future; one is in the near future, $\approx 37$ years time from now, and one is much later, $\approx 88$ years time from now.

\section{Fitting the CLIMEX parameters and using Arc Map v.10}

In the present study, we used distribution data of both Aedes aegypti and of some dengue cases (where there was a lack of Aedes aegypti data), temperature and moisture indices and cold and dry stresses, in order to fit the CIMEX parameters, because we felt these data could produce a model that better approximated the 
potential distribution. All of the parameters were fitted to the known and naturalized distribution of dengue and Aedes aegypti. Each parameter was adjusted iteratively to satisfy agreement with the Aedes distribution, and the fitted parameters were checked to ensure that they were reasonable.

Many studies have suggested that Aedes mosquitoes are critically dependent on temperature, and that temperature ranges from $14-18^{\circ} \mathrm{C}$ at the lower end, and $35-40^{\circ} \mathrm{C}$ at the upper end can lead to higher transmission occurrence [59]. In Saudi Arabia, Khormi et al. [5] found that a minimum temperature range from 18 to 25 was suitable for mosquito survival and that the Aedes mosquito survival rate increased at higher temperatures (but at not more than $38^{\circ} \mathrm{C}$ ). Wayne and Graham [60] and Conner [61] found that Aedes aegypti was most active within a range of temperatures between $15^{\circ} \mathrm{C}$ and $30^{\circ} \mathrm{C}$. Other field observations and laboratory tests have determined the survival rates to be from about $18^{\circ} \mathrm{C}$ to not more than $38^{\circ} \mathrm{C}$, based on daily or monthly data of minimum and maximum temperatures [6-8].

Therefore, we set the limiting low temperature (DV0) at 18, the lower optimal temperature (DV1) at 25, the upper optimal temperature (DV2) at 32, and the limiting high temperature (DV3) at 38. These sets provided the best fit to the observed distribution of dengue and Aedes aegypti.

The lowest limiting moisture (SM0) was set at 0 because it represents permanent wilting point and this number provided a good fit with the observed distribution of Aedes aegypti and dengue in drought areas, such Saudi Arabia, Somalia, Sudan and Yemen. The lower (SM1) and upper (SM2) optimum moisture and the highest limiting moisture were set at $0.2,0.5$ and 4, respectively, if species growth was to be increased in the west of Yemen, west and south west Saudi Arabia and the south and east of Sudan. Additionally, these values provided an appropriate fit to the observed distributions.

The heat stress parameter (TTHS) was set at $38^{\circ}$ $\mathrm{C}$ because it is reported that in some countries, such as Saudi Arabia and Somalia, Aedes aegypti is able to survive up to this temperature $[4,5]$. The heat stress accumulation rate (THHS) was set at 0.9 week $^{-1}$, which allows Aedes aegypti to persist along the west and south west of Saudi Arabia and in the east of Somalia.

The dry stress parameter was set at 0.001 for the dry stress threshold (SMDS) and -0.001 week ${ }^{-1}$ for the dry stress rate (HDS), because these adjusted values provided an appropriate fit to the observed distribution.

For a more efficient visualization of the potential and future distributions around the world, we transferred the results of the Ecoclimatic Index (EI) to Arc Map version 10.3 EI can only be converted as a point feature, each point having an EI value. We then converted the point feature to a raster and used the EI values to assign values to the output raster. Raster surfaces are effective in identifying where favorable climate areas are concentrated, by highlighting areas based on the EI resulting from the CLIMEX analysis.

\section{Results}

The resultant historical model shows favorability to Aedes aegypti and dengue transmission within most of its known areas in Saudi Arabia, Somalia, Sudan, Djibouti and Yemen (Figure 2). Comparing Figures 1 and 2, we see that the current distribution of Aedes aegypti and dengue in the study area are almost consistent with the EI values resulting from the predicted models. All of Somalia and Djibouti, the southern part of Sudan, the middle to south west 


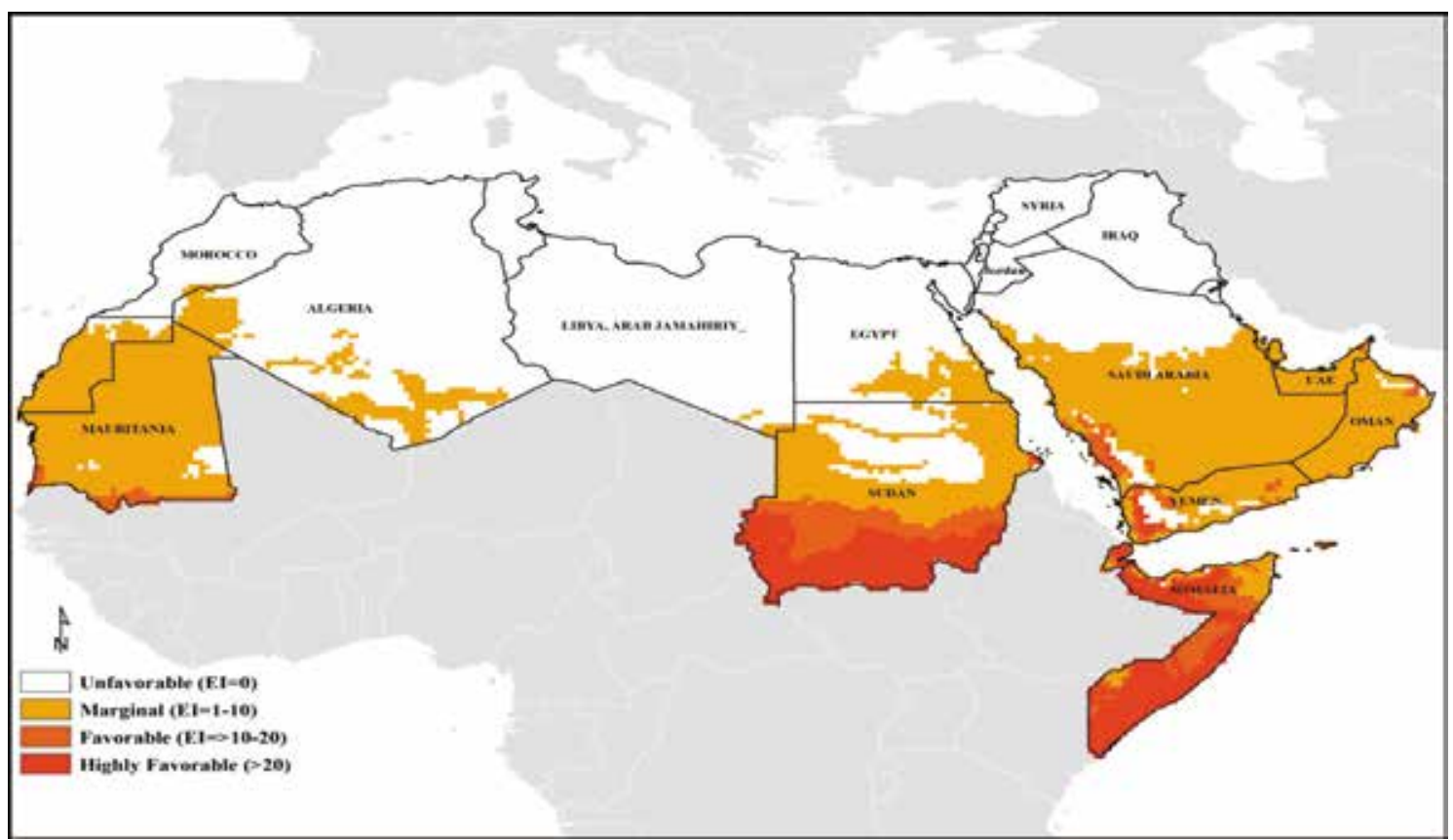

Figure 2: The climate (EI) for Aedes aegypti based on CLIMEX for reference climate (averaging period 1950-2000).

coast of Saudi Arabia, and the western coast of Yemen are modeled as having favorable $(\mathrm{EI}=10-20)$ to highly favorable $(\mathrm{EI}=>20)$ climate conditions for Aedes aegypti and dengue transmission.

Small areas in the south of Mauritania, north east of Oman and part of east Yemen are projected to have favorable conditions $(E I=>10-20)$. Much of the area of Saudi Arabia, Oman, UAE, Mauritania, the middle and east of Sudan, and the southeast of Egypt have marginal conditions (EI=1-10). Iraq, Syria, Jordan and Lebanon and most of Libya, Algeria and Morocco are modeled as having unfavorable conditions $(\mathrm{EI}=0)$. This high correlation between the modeled result (Figure2) and the actual recorded data (Figure1) shows that the correct parameter values have been selected for CLIMEX modeling.

In the future models, we observed a reduction or contraction of the very favorable climate areas generally. In 2050, high contraction in very favorable conditions was observed along the western coasts of Saudi Arabia and Yemen, south of Sudan and Somalia with the CS model (Figure 3), while less contraction was observed in these areas with the MR model (Figure 4). However, both models indicate a reduction in the areas with very favorable climate, and this trend is observed to be further increased by 2100 (Figures 3, 4, 5, 6).

While these areas are likely to have changed from very favorable to favorable by 2050 and to marginal climate areas by 2100 , new areas of favorable climatic conditions are observed to appear in the north east of Oman and UAE, the west of Yemen (Figures 3 and 4) and the north of Libya (Figure 6). This was clearly observed in both models, but the changes were greater in the CS model as compared with the MR model. This trend is expected to be further increased by 2100 according to the CS model but to be reduced according to the MR model (Figures 5 and 6). 


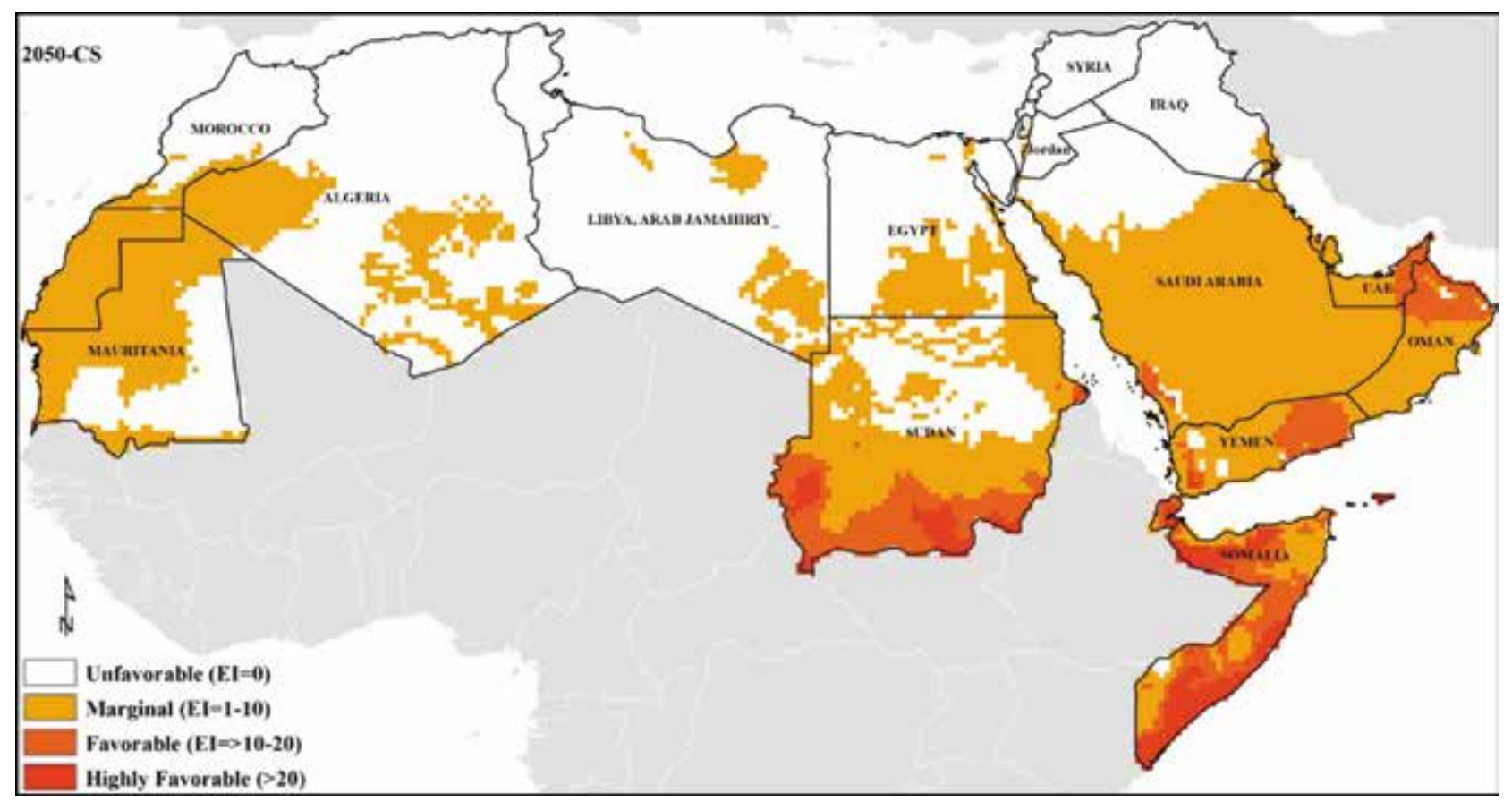

Figure 3: The climate (EI) for Aedes aegypti and dengue transmission in the 2050s based on CLIMEX under the CSIRO-Mk3.0 GCM running the SRES A2 scenario.

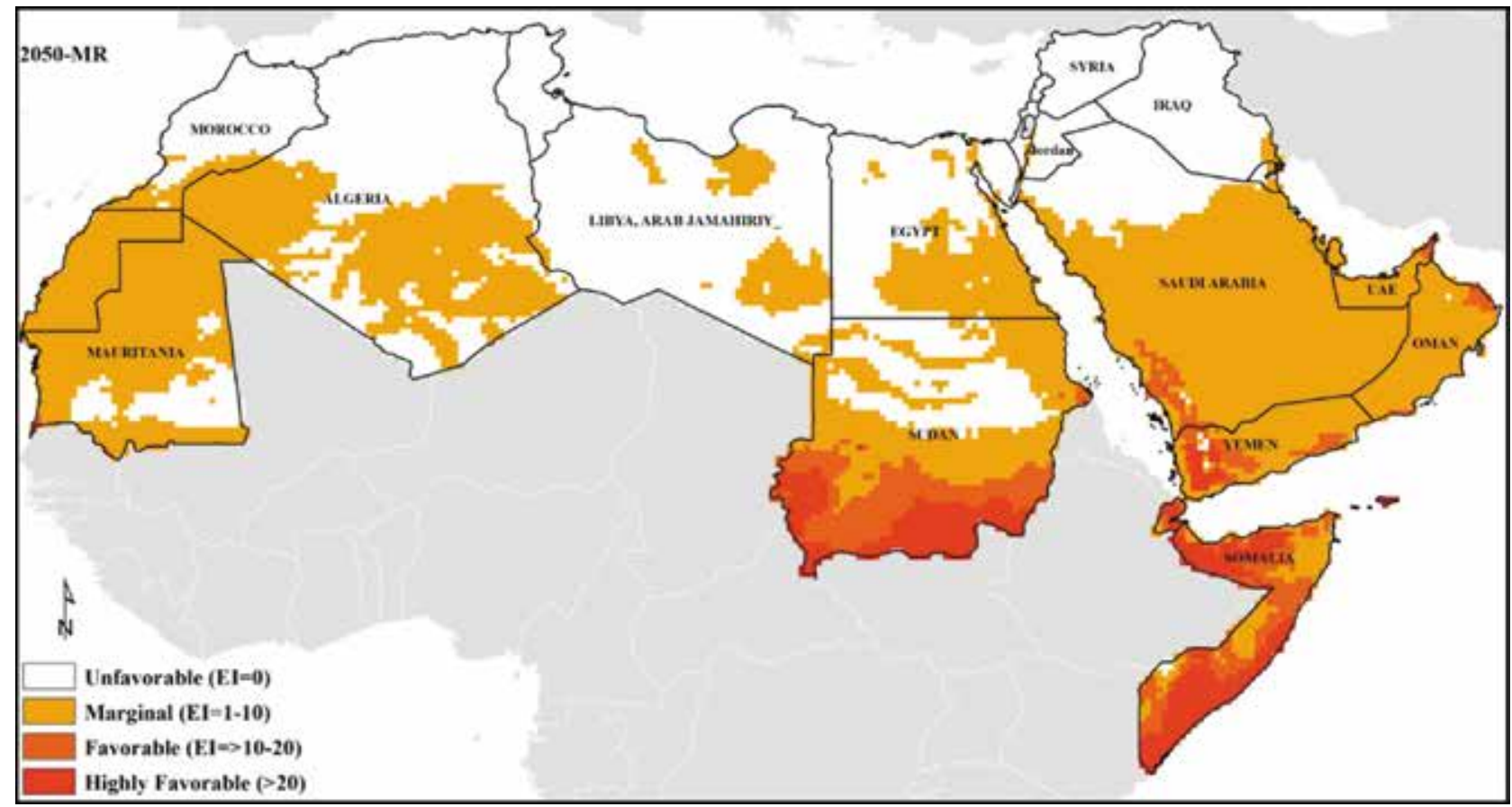

Figure 4: The climate (EI) for Aedes aegypti and dengue transmission in the 2050s based on CLIMEX under the MIROC-H GCM running the SRES A2 scenario. 


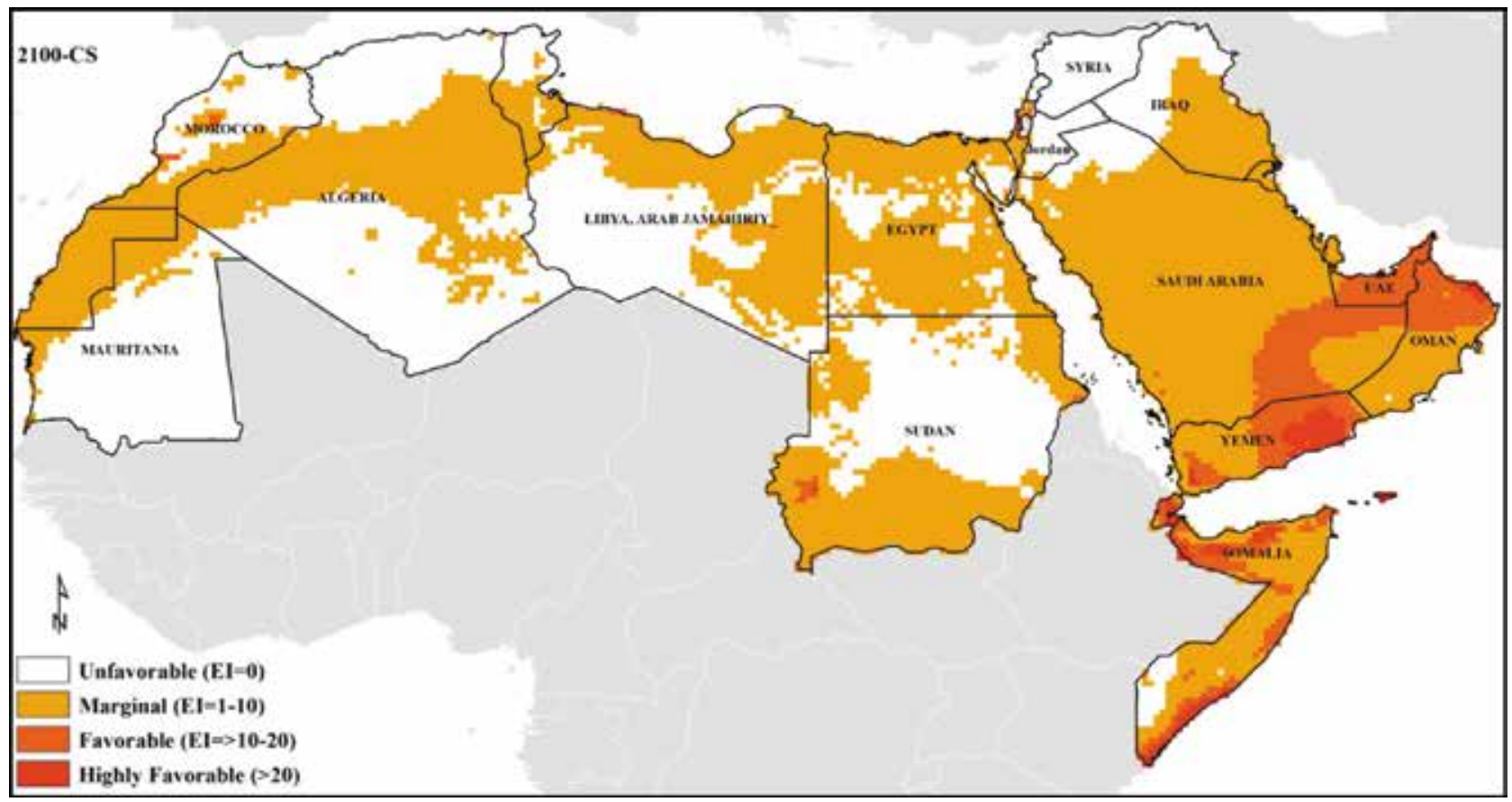

Figure 5: The climate (EI) for Aedes aegypti and dengue transmission in the 2100s based on CLIMEX under the CSIRO-Mk3.0 GCM running the SRES A2 scenario.

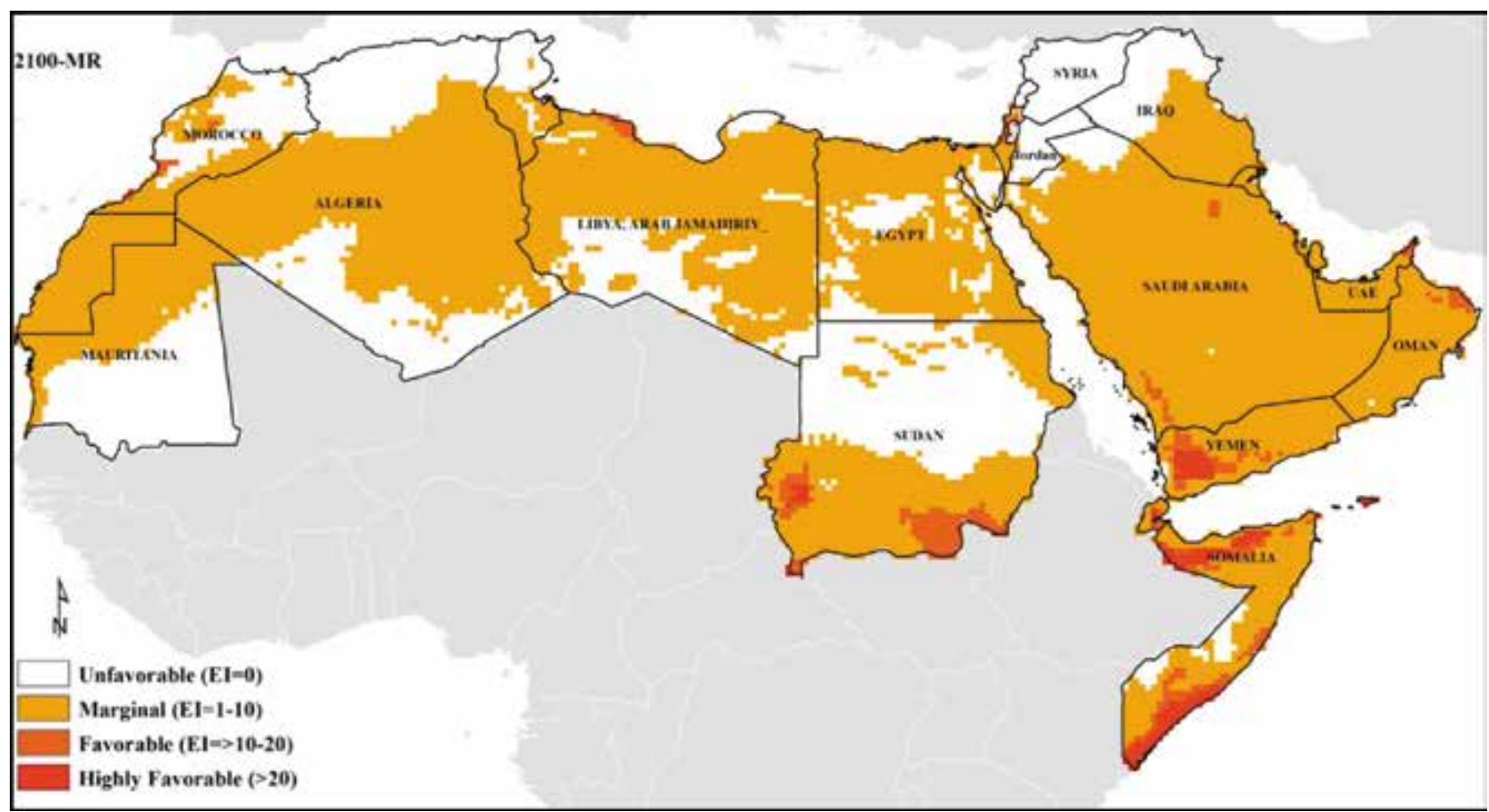

Figure 6: The climate (EI) for Aedes aegypti and dengue transmission in the 2100s based on CLIMEX under the MIROC-H GCM running the SRES A2 scenario. 
Figure 5 (2100 CS) shows that some of these areas, e.g. east of Yemen, are likely to be changed from favorable to very favorable, while Figure 6 (2100 MR) shows a reverse climatic condition (from favorable to marginal). Figure 6 also shows that some parts of western Yemen, the north and southeast coast of Somalia, and small areas in the south of Sudan will continue with favorable climatic conditions. A similar pattern is observed in 2100 under CS, but with greater contraction of the areas.

By 2050, both models show an increase in the marginal climate areas in most of the Arab World countries. This trend is expected to be exacerbated by 2100 , especially in all the Arabian Gulf countries and the countries south of the Mediterranean Sea.

\section{Discussion}

Using current climatic conditions and considering future climatic scenarios, by using CLIMEX, we have attempted to model the most favorable climatic conditions and likely areas for Aedes aegypti and dengue transmission in the Arab World. The current model has a good fit with the current distribution records of Aedes and dengue, which were gathered for model validation purposes. Under current climatic conditions, the model shows some areas in the west and southwest of Saudi Arabia, west of Yemen, Somalia, Djibouti and South of Sudan as having favorable to highly favorable conditions for the mosquito and for dengue transmission.

The south of Mauritania is projected to have favorable climatic conditions for Aedes aegypti and dengue transmission, significantly exceeding the currently known distribution for that area. This could be due to a lack of records from this region. Other non-climatic factors, such as a lack of dispersal opportunities, could also inhibit Aedes aegypti from spreading in this region.
These results highlight areas where more detailed risk assessments of the mosquito population may be prudent. Effective implementation of a mosquito monitoring system, together with a public education campaign, may contribute towards more effective management in this region. Models, such as the ones produced in this study, can be useful tools in public awareness campaigns so as to enlist the help of health authorities in the management of existing infestations and in the prevention of further mosquito dispersal.

Cold and dry stresses could be the main factors limiting the mosquito distribution and dengue transmission and preventing its establishment in much of the Arabian Peninsula, Egypt, Libya, Morocco and Algeria. Within the marginal areas, identified as covering much of Saudi Arabia, Yemen, Oman, UAE, Mauritania, eastern Sudan and south east Egypt, Aedes and dengue are patchily distributed, and restricted to favorable microhabitats. Thus in these areas, the mosquitoes pose limited threat, and dispersal is likely to be very slow.

The possible changes indicted by the results of the climate change modeling give an overview of the potential future distribution of Aedes aegypti and dengue transmission. Some areas where the mosquito and dengue currently occur may become climatically unsuitable as the climate changes. All the scenarios considered in this study indicate an overall contraction in the climatically suitable areas for Aedes in the future (Figures 3 to 6). Some of this reduced potential area for Aedes aegypti and dengue covers currently important hotspots (e.g. Somalia and southern Sudan). These results may be useful in making informed choices about the allocation of resources for mosquito control by highlighting areas where climate suitability is expected to decrease in the future.

This study has identified new areas of the Arab 
World that may be at risk for Aedes aegypti and dengue transmission due to changes in climate in the future, and which may warrant strategic control measures to prevent its spread. Although an overall reduction in the potential distribution is projected for the west of Saudi Arabia, west of Yemen, south of Sudan and Somalia under future climate scenarios examined here, the potential for range expansion in the north east and east of Oman, and in the UAE and a small area in the north of Libya was identified. Such areas may require more detailed risk assessment regarding the spread of mosquitoes. The assessment and management of mosquito risk depends to a large extent on projections of habitat suitability, so that threat levels can be assessed. The response of Aedes aegypti and dengue transmission to changes in climate must form an integral part of such assessments. Particularly, areas that are currently at risk and that will continue to be at risk from the mosquito in the future, are identified in this study. Monitoring of these areas could be important, especially in the hotspots of Djibouti and the north and east coast of Somalia and the west of Yemen. Our results can be used in the decision-making processes by health managers in prioritizing areas for eradication, and in determining areas where containment would be cost-effective.

Computer simulation modeling can provide an important adjunct to the management of a complicated disease system and to the traditional methods of investigation. It is useful in evaluating long term climate variability, for which prospective studies lack feasibility, and historical studies lack similarity [14, 62].

Other etiologic factors, such as urbanization, population density, poverty, inadequate mosquito control, absence of water systems, and international travel or migration, that are not addressed at this level of integrated modeling, should ultimately be incorporated to determine human risk from dengue fever and its vector [4]. Future integrated models should attempt to account for these site specific factors as well [63] while climatic conditions contribute to epidemic spread and geographic distribution of dengue [19, 64].

Many climatologists believe in the reality of climate change, and if these occur, there is the potential for an increase in dengue carrying mosquitoes transmitting the virus to susceptible human populations in the future. The models suggest that endemic locations may be at the greatest risk from hemorrhagic dengue if the transmission intensity increases. Other factors, such as the source of infection, the mosquito population size, and a susceptible human population would also need to be present for a dengue epidemic to occur under suitable climatic conditions. Where and when dengue occurs in the future will depend on a number of different economic, social and environmental factors [11].

\section{Conclusion}

In this study, we present the favorable climatic locations for Aedes aegypti and dengue transmission to survive, and do not predict the actual future distribution. Our models are useful for management and monitoring purposes, especially under conditions of future climate change. We can adapt them for informing decisions regarding allocating resources for controlling dengue risk towards areas where risk infection remains, and away from areas where climatic suitability is likely to decrease in the future.

The models developed in the study can help reduce the challenges faced by national health services in the Arab World; especially where they are improving the early detection of 
mosquito favorable areas, of dengue transmission and prevention of dengue fever. The strategy presented here should be supported by an adequate surveillance system for this viral disease to prevent the spread of it.

These models would be helpful to inform the prioritizing of dengue management initiatives in current risk areas, and in those that will remain risk locations in the future. Other issues include excessive resource consumption in rich countries, an increase in social inequality and population increases in poor countries, all of which should be taken into account since addressing these issues will also help to reduce the mosquito risk, and dengue prevalence.

\section{Competing interests}

The author declares that he has no competing interests.

\section{Acknowledgement}

Author thanks Jazan University, University of New England and Umm Al Qura University for providing him access to their library databases and labs.

\section{References}

1. Hopp MJ, Foley JA: Global-scale relationships between climate and the dengue fever vector, Aedes aegypti. Climate Change 2001, 48: 441-463.

2. Haines A, Kovats RS, Campbell-Lendrum, $\mathrm{D}$, Corvalan $\mathrm{C}$ : Climate change and human health: impacts, vulnerability and public health. Public Health 2006, 120: 585-596.

3. Hales S, de Wet N, Maindonald J, Woodward A: Potential effect of population and climate changes on global distribution of dengue fever: an empirical model. Lancet 2002; 360: 830-834.

4. Gubler DJ and Clark GG: Dengue/Dengue
Hemorrhagic Fever: The Emergence of a Global Health Problem. Emerg Infect Dis 1995, 1:55-57.

5. Khormi HM, Kumar L, Elzahrany R: Describing and analyzing the association between meteorological variables and adult Aedes aegypti mosquitoes. J Food Agr Environ 2011, 9: 954-959.

6. Bliss AR, Gill JM: The effects of freezing on the larvae of Aedes aegypti. Amer J Trop Med Hyg 1933, 13: 583-588.

7. Christophers S R: Aedes aegypti (L.) The Yellow Fever Mosquito. Its Life History, Bionomics and Structure. University Press, Cambridge; 1960.

8. Macfie, JWS: Heat and Stegomyia fasciata, Short Exposures to Raised Temperatures. Ann Trop Med Parasitol 1920, 14:73-82.

9. Rueda LM, Patel KJ, Axtell RC, Stinner RE: Temperature-dependent development and survival rates of Culex quinquefasciatus and Aedes aegypti (Diptera: Culicidae). J Med Entomol 1990, 27: 892-898.

10. Githeko AK, Lindsay SW, Confalonieri UE, Patz JA: Climate change and vector-borne diseases: A regional analysis. Bulletin of the World Health Organization 2000, 78:1136-1147.

11. Khormi MH, Kumar L: Examples of using spatial information technologies for mapping and modelling mosquito-borne diseases based on environmental, climatic, socioeconomic factors and different spatial statistics, temporal risk indices and spatial analysis: A review. Journal of Food, Agriculture and Environment 2011a, 9(2):41-49.

12. Day JF, Curtis GA: Influence of rainfall on Culex nigripalpus (Diptera, Culicidae) bloodfeeding behavior in Indian River County, Florida. Annals of the Entomological Society of 
America 1989, 82:32-37.

13. Johansson MA, Dominici F, Glass GE: Local and Global Effects of Climate on Dengue Transmission in Puerto Rico. PLOS Negl Trop Dis 2009, 3(2): e382. doi:10.1371/ journal.pntd.0000382.

14. Patz JA, Martens WJM, Focks DA, and Jetten TH: Dengue Fever Epidemic Potential as Projected by General Circulation Models of Global Climate Change. Environ. Health Perspect 1998,106, 147-153.

15. IPCC (Intergovernmental Panel on Climate Change): Climate Change 2007: The physical science basis. Contribution of Working Group I to the Fourth Assessment Report of the Intergovernmental Panel on Climate Change. Edited by Solomon S, Qin D, Manning M, Chen Z, Marquis M, Averyt KB, Tignor M, and Miller HL. 2007, Cambridge University Press, Cambridge and New York.

16. Jetten TH and Focks DA: Potential Changes in the Distribution of Dengue Transmission under Climate Warming. Amer. J. Trop. Med. Hyg 1997, 57, 285-297.

17. Martens WJM, Jetten TH, Focks DA: Sensitivity of malaria, schistosomiasis, and dengue to global warming. Clim Change 1997, 35: 145-156.

18. Patz JA, Epstein PR, Burke TA, and Balbus J M: Global Climate Change and Emerging Infectious Disease. J Amer Med Assoc 1996, 275: 217-223.

19. Reiter P: Weather, vector biology, and arboviral recrudescence. In: The Arboviruses: Epidemiology and Ecology, vol 1 (Monath TP, ed). Boca Raton, FLCRC Press; 1988: 245-255.

20. Hales S, Weinstein P, Woodward A: Dengue fever epidemics in the South Pacific: driven by EI Niño Southern Oscillation? Lancet 1996,
Dec 14; 348(9042):1664-1665.

21. Al-Ghamdi K, Khan MA, and Mahyoub $\mathrm{J}$ : Role of climatic factors in the seasonal abundance of Aedes aegypti L. and dengue fever cases in Jeddah province of Saudi Arabia. Current World Environment 2009, 4:307-312.

22. Abdalmagid MA and Alhusein SH: Entomological investigation of Aedes aegypti in Kassala and Elgadarief States, Sudan. Sudanese Journal of Public Health 2008, 3 (2): 77-80.

23. Mohamed E, Mohsin N, Al-Abri S, Obaidani I, Jha A, Kamble $P$, et al: Acute renal failure in a patient with both dengue fever and leptospirosis. Oman Med J. 2008, 23:101-3.

24. Ayyub M, Khazindar A M, Lubbad E H, Barlas S, Alfi AY, and Al-Ukayli S: Characteristics of dengue fever in a large public hospital, Jeddah, Saudi Arabia. J Ayub Med Coll Abbottabad 2006; 18: 9-13.

25. Bin Ghouth AS, Ananda A, Letson GW: Dengue Outbreak in Hadramout, Yemen, 2010: An Epidemiological Perspective. $A m J$ Trop Med Hyg 2012, 86 (6): 1072-1076.

26. Al-Araimi H, Al-Jabri A, Mehmoud A and Al-Abri Seif: Dengue Haemorrhagic Fever presenting as Acute Abdomen. Sultan Qaboos Univ Med J 2011; 11(2): 265-268.

27. Aburas HM:ABURAS Index: Astatistically developed index for dengue-transmitting vector population prediction. Proceedings of World Academy of Science, Engineering and Technology 2007, 23:151-154.

28. El-Badry A and Al-Ali K: Prevalence and Seasonal Distribution of Dengue Mosquito, Aedes aegypti (Diptera: Culicidae) in Al-Madinah Al-Munawwarah, Saudi Arabia. Journal of Entomology 2010, 7(2): 80-88.

29.Sharp TW, Wallace MR, Hayes CG, Sanchez 
JL, De Fraites RF, Arthur RR, Thornton SA, Batchelor RA, Rozmajzl PJ, Hanson RK: Dengue fever in U.S. troops during Operation Restore Hope, Somalia, 1992-1993. The American Journal of Tropical Medicine and Hygiene 1995, 53(1):89-94.

30. IPCC Special Report on Emissions Scenarios: A Special Report of Working Group III of the Intergovernmental Panel on Climate Change. Cambridge, UK; 2000.

31. Wharton TN, Kriticos DJ: The fundamental and realized niche of the Monterey Pine aphid,Essigella californica (Essig) (Hemiptera: Aphididae): implications for managing softwood plantations in Australia. Diversity and Distributions 2004, 10: 253-262.

32. Taylor S, Kumar L, Reid N, Kriticos DJ: Climate Change and the Potential Distribution of an Invasive Shrub, Lantana camara L. PLOS ONE 2012, 7(4): e35565. doi:10.1371/journal. pone. 0035565 .

33. Chejara VK, Kriticos DJ, Kristiansen P, Sindel BM, Whalley RDB, et al : The current and future potential geographical distribution of Hyparrhenia hirta. Weed Research 2010, 50:174-184.

34. Poutsma J, Loomans AJM, Aukema B, Heijerman $\mathrm{T}$ : Predicting the potential geographical distribution of the harlequin ladybird, Harmonia axyridis, using the CLIMEX model. BioControl 2008, 53:103-125.

35. Sutherst RW, Bourne AS: Modelling nonequilibrium distributions of invasive species: a tale of two modelling paradigms. Biological Invasions 2009, 11: 1231-1237.

36. Kriticos DJ, Yonow T, McFadyen RE: The potential distribution of Chromolaena odorata (Siam weed) in relation to climate. Weed Research 2005, 45: 246-254.

37. Centre for Disease Control and Prevention
(CDC). Accessed 2012. http://www.healthmap. org/dengue/index.php

38.Center for International Earth Science Information Network (CIESIN). Accessed 2012. [http://www.ciesin.org/docs/001-613/map15. gif].

39. Gratz NG: Critical review of the vector status of Aedes albopictus. Medical and Veterinary Entomology 2004, 18:215-227.

40. Gubler DJ, Trent DW: Emergence of epidemic dengue/dengue hemorrhagic fever as a public health problem in the Americas. Infect Agents Dis 1994, 2:383-93.

41. Gubler DJ: Resurgent Vector-Borne Diseases as a Global Health Problem. Emerg Infect Dis 1998a, 4: 442-450.

42. Gubler DJ: Dengue and dengue hemorrhagic fever. Clinical Microbiology Reviews. 1998b, 11:480-496.

43. Gubler DJ: The global emergence/ resurgence of arboviral diseases as public health problems. Archives of Medical Research 2002; 33:330-342.

44. Gubler DJ. Aedes albopictus in Africa. The Lancet 2003, 3:751-752.

45. Gubler DJ. The changing epidemiology of yellow fever and dengue 1900 to 2003: full circle? Comparative Immunology, Microbiology and Infectious Diseases 2004, 27:319-330.

46. Gubler DJ, Kuno G: Dengue and Dengue Hemorrhagic Fever. $C A B$ International; London: 1997.

47. Lounibos LP: Invasions by insect vectors of human disease. Annual Review of Entomology 2002; 47:233-266.

48. Medlock JM, Snow KR, Leach S: Potential transmission of West Nile virus in the British Isles: an ecological review of candidate mosquito bridge vectors. Medical and 
Veterinary Entomology 2005, 19:2-21.

49. Moore CG: Aedes albopictus in the United States: current status and prospects for further spread. Journal of the American Mosquito Control Association 1999, 15:221-227.

50. Moore CG, Mitchell CJ: Aedes albopictus in the United States: ten-year presence and public health implications. Emerging Infectious Diseases 1997, 3:329-334.

51. Rogers DJ, Wilson AJ, Hay SI, Graham AJ: The Global Distribution of Yellow Fever and Dengue. $A d v$ Parasitol 2006, 62:181-220. doi:10.1016/S0065-308X(05)62006-4.

52. Al Thbiani Aziz, Hamady Dieng, Ahmad Abu Hassan, Tomomitsu Satho, Fumio Miake, Md Rawi, Che Salmah, Sazaly AbuBakar: Insecticide susceptibility of the dengue vector Aedes aegypti (Diptera: culicidae) in Makkah City, Saudi Arabia. Asian Pacific Journal of Tropical Disease 2011, 1(2): 94-99.

53. Rodier G R, Gubler D J, Cope S E, Cropp CB, Soliman AK, Polycarpe D, Abdourhaman MA, Parra JP, Maslin J, Arthur R R: Epidemic dengue 2 in the city of Djibouti 1991-1992. Trans R Soc Trop Med Hyg 1996, 90: 237-240.

54. Rathor, HR: The Role of Vectors in Emerging and Re-emerging Diseases in the Eastern Mediterranean Region. Dengue Bulletin 2000, 24:103-109.

55. AndrewarthaHG, Birch LC: The distribution and abundance of animals. Chicago: University of Chicago Press; 1954, 782.

56. Sutherst RW, Maywald G, Kriticos DJ: CLIMEX Version 3: User's Guide. Melbourne: Hearne Scientific Software Pty Ltd; 2007.

57. Gordon HB, Rotstayn LD, McGregor JL, Dix MR, Kowalczyk EA, et al: The CSIRO Mk3 Climate System Model, CSIRO Atmospheric Research Technical Paper No. 60. CSIRO
Atmospheric Research, Aspendale; 2002.

58. Kriticos DJ, Webber BL, Leriche A, Ota $\mathrm{N}$, Macadam I, et al: CliMond: global highresolution historical and future scenario climate surfaces for bioclimatic modelling. Methods in Ecology and Evolution; 2011.

59. Wallis RC: A GIS model for predicting potential "high risk" areas of West Nile virus by identifying ideal mosquito breeding habitats. M.Sc. thesis. Environmental Science, Mississippi State University, Mississippi; 2005.

60. Wayne AR and Graham CL: The Effect of Temperature and Relative Humidity on the Flight Performance of Female Aedes aegypti. J Insect Physiol 1968, Vol. 14: 1251-1257.

61. Connor ME: Suggestions for developing a campaign to control yellow fever. $A m J$ Trop Med 1924, 4:277-307.

62. Martens WJM, Jetten TH, Rotmans J, and Niessen LW: Climate Change and Vector Borne Diseases. Global Environ Change 1995, 5: 195-209.

63. Lifson AR: Mosquitoes, models, and dengue. Lancet (North American Edition) 1996, 347: 1201-1202.

64. Reiter P, Gubler DJ: Surveillance and control of urban dengue vectors. In: Gubler DJ, Kuno G, eds. Dengue and dengue hemorrhagic fever. Wallingford, UK: CAB International; 1997: 425-62. 